\title{
Dexamethasone Suppression Test and MMPI Scales
}

\author{
Marc Ansseau ${ }^{\mathrm{a}}$, Remy von Frenckell ${ }^{\mathrm{a}}$, Georges Franck ${ }^{\mathrm{a}}$, Vincent Geenen ${ }^{\mathrm{b}}$, Jean-Jacques Legros ${ }^{\mathrm{b}}$ \\ ${ }^{a}$ Biological Psychiatry and Psychopharmacology Unit and ${ }^{b}$ Psychoneuroendocrinology Unit, University of Liège, Belgium
}

Key Words. Dexamethasone suppression test · Minnesota Multiphasic Personality Inventory · Major depression

\begin{abstract}
In 42 major depressive inpatients, we analyzed the relationship between dexamethasone suppression test (DST) results and Minnesota Multiphasic Personality Inventory (MMPI) scales. Cortisol levels following DST were positively correlated with the depression as well as the social introversion MMPI scale scores, and negatively correlated with the hypomania scale scores. DST nonsuppressor depressives $(n=15)$ exhibited significantly higher scores on the social introversion scale and significantly lower scores on the hypomania subscale than DST suppressors $(\mathrm{n}=27)$. Moreover, stepwise discriminant analysis using the hypomania score was able to correctly classify $71 \%$ of the sample according to DST dichotomy, whereas the association of other scales did not significantly improve the classification. Therefore, these results support a relationship between DST and depressive/manic psychopathology rather than anxious psychopathology.
\end{abstract}

\section{Introduction}

The overnight dexamethasone suppression test (DST) currently represents the most widely used biological marker for major, primary, or endogenous depression [review in 1]. About $50 \%$ of major, primary, or endogenous depressives exhibit an abnormal cortisol 'escape' from dexamethasone suppression; however, the specificity of this phenomenon is still debated [review in 2].

Controversial data also exist concerning possible clinical correlates of DST nonsuppression. Some authors have reported an association between DST nonsuppression and severity of depression [3-5] while some other authors found a relationship between nonsuppression and anxiety or stress symptoms $[4,6]$. However, most studies did not support particular association between severity of depression or anxiety and DST nonsuppression [7-15] but some results implicated a role for age [10,13], agitation [7] or psychotic symptoms [11, 16-19].

The Minnesota Multiphasic Personality Inventory (MMPI) represents the most widely used and best validated measure of psychopathology and personality functioning for psychiatric populations. The studies comparing MMPI scale scores between DST suppressor and nonsuppressor depressives yielded controversial results: lack of difference $[20,21]$, elevated scores on the hypo- chondriasis, depression, hysteria and schizophrenia scales among suppressor depressives [22], and higher score on the social introversion subscale among nonsuppressor depressives [13].

Therefore, the purpose of our study was to assess the relationship between cortisol level after DST and MMPI scales and to compare MMPI self-ratings of DST suppressor and nonsuppressor major depressive patients. Specifically, we wanted to assess a possible preferential relationship of DST nonsuppression with depressive or anxious psychopathology.

\section{Methods}

Subjects

The study was performed in 42 depressive inpatients representing consecutive admissions to the Biological Psychiatry and Psychopharmacology Unit of the University Hospital of Liège, Belgium. All patients fulfilled Research Diagnostic Criteria (RDC) for a definite major depressive episode [23] and had a score of at least 20 on the 21-item Hamilton depression scale. The sample included 22 males and 20 females, with age ranging from 19 to 66 years (mean age $=44.6$ years \pm 12.9 ).

Patients were free of medical illness, as evidenced by history, physical examination, EKG, EEG, chest X-ray and routine laboratory tests. They had also been free of any medication for at least 2 weeks at the time of the study, and they gave informed consent. 


\section{Procedure}

The DST was performed according to the simplified procedure described by Carroll et al. [24]: oral intake of $1 \mathrm{mg}$ dexamethasone at 11 p.m. and blood collection at 4 p.m. on the following day. Cortisol was measured by radioimmunoassay, using ${ }^{125}$ I-cortisol (Farmos Diagnostica, Finland) and anticortisol antiserum (made against the 3-CMO-BSA conjugate), as described previously [25]. All assays were processed in duplicate, with maximum intra- and interassay coefficients of variation of 4.3 and $8.3 \%$, respectively.

According to Carroll et al. [24], DST nonsuppression was defined by a cortisol level higher than $5 \mu \mathrm{g} / \mathrm{dl}$.

Automated MMPI [26] was performed within 2 days of the DST.

\section{Data Analysis}

The relationships between MMPI scale scores and cortisol levels (transformed in logarithms in order to normalize their distribution) were assessed by Pearson's correlation coefficient, while the mean scores among suppressor and nonsuppressor depressives were compared using group $t$ tests. Finally, a stepwise discriminant analysis was performed with DST suppression or nonsuppression as the independent variable and MMPI scale scores and age as the dependent variables.

\section{Results}

Following DST, 15 patients exhibited cortisol nonsuppression (35.7\%). There was no significant difference between suppressors and nonsuppressors with regard to sex distribution. However, DST nonsuppressors were significantly older than DST suppressors $(50.5 \pm 12.1$ vs. $41.3 \pm 12.3, t=2.3, p<0.05$ ).

Pearson's correlation coefficients between individual cortisol levels following DST and MMPI scale scores are presented in table I, while the comparison of MMPI scale scores between DST suppressor and nonsuppressor depressives is presented in table II.

Post-DST cortisol levels were positively correlated with the depression as well as the social introversion MMPI scale scores $(\mathrm{p}<0.05)$ and negatively correlated with the hypomania scale scores $(\mathrm{p}<0.005)$. Moreover, cortisol levels were also correlated with age $(r=0.34, p<$ $0.05)$. DST nonsuppressor depressives exhibited significantly higher scores on the depression and the social introversion scales $(\mathrm{p}<0.05)$ and significantly lower scores on the hypomania scale $(\mathrm{p}<0.001)$ than DST suppressor depressives. Stepwise discriminant analysis using the hypomania score was able to correctly classify $71 \%$ of the sample according to DST dichotomy ( $70 \%$ of suppressors and $73 \%$ of nonsuppressors). The other parameters did not significantly improve the classification.
Table I. Pearson correlation coefficients between individual cortisol levels after DST (log-transformed data) and MMPI scale scores in 42 major depressives

\begin{tabular}{lc}
\hline IN (indecision) & 0.08 \\
\hline L (lie) & -0.04 \\
\hline F (rare endorsement) & -0.08 \\
\hline K (correction) & 0.04 \\
\hline HS (hypochondriasis) & -0.01 \\
\hline D (depression) & $0.34^{*}$ \\
\hline HY (hysteria) & 0.06 \\
\hline PD (psychopathic deviate) & -0.22 \\
\hline MF (masculinity-feminity) & 0.02 \\
\hline PA (paranoia) & -0.17 \\
\hline PT (psychasthenia) & 0.25 \\
\hline SC (schizophrenia) & -0.19 \\
\hline MA (hypomania) & $-0.47^{* *}$ \\
\hline SI (social introversion) & $0.33^{*}$ \\
\hline AT (anxiety) & 0.06 \\
\hline ES (ego strength) & -0.10 \\
\hline${ }^{*}$ p < $0.05 ; * * p<0.005$. & \\
\hline
\end{tabular}

Table II. Comparison of MMPI scale scores between DST suppressor (S) and nonsuppressor (NS) major depressives (mean \pm standard deviation)

\begin{tabular}{llll}
\hline & $\begin{array}{l}\mathrm{S} \\
(\mathrm{n}=27)\end{array}$ & $\begin{array}{l}\mathrm{NS} \\
(\mathrm{n}=15)\end{array}$ & $\mathrm{T}$ \\
\hline IN (indecision) & $52.2 \pm 5.3$ & $52.5 \pm 5.3$ & 0.2 \\
\hline L (lie) & $49.4 \pm 13.1$ & $49.7 \pm 6.7$ & 0.1 \\
\hline F (rare endorsement) & $66.9 \pm 12.1$ & $61.5 \pm 14.4$ & 1.3 \\
\hline K (correction) & $49.5 \pm 12.2$ & $51.6 \pm 11.8$ & 0.5 \\
\hline HS (hypochondriasis) & $68.2 \pm 13.8$ & $69.6 \pm 12.2$ & 0.3 \\
\hline D (depression) & $72.9 \pm 12.9$ & $81.6 \pm 11.6$ & $2.2^{*}$ \\
\hline HY (hysteria) & $68.2 \pm 12.2$ & $70.8 \pm 7.2$ & 0.9 \\
\hline PD (psychopathic deviate) & $69.4 \pm 10.9$ & $63.4 \pm 10.7$ & 1.7 \\
\hline MF (masculinity-feminity) & $51.4 \pm 10.5$ & $50.9 \pm 9.6$ & 0.1 \\
\hline PA (paranoia) & $74.6 \pm 16.1$ & $69.8 \pm 11.3$ & 0.9 \\
\hline PT (psychasthenia) & $74.7 \pm 12.1$ & $79.6 \pm 10.6$ & 1.3 \\
\hline SC (schizophrenia) & $83.3 \pm 15.9$ & $77.0 \pm 12.9$ & 1.4 \\
\hline MA (hypomania) & $66.3 \pm 11.7$ & $53.4 \pm 10.5$ & $3.6^{* *}$ \\
\hline SI (social introversion) & $55.8 \pm 12.6$ & $64.5 \pm 12.0$ & $2.2^{*}$ \\
\hline AT (anxiety) & $67.4 \pm 10.6$ & $68.0 \pm 8.6$ & 0.2 \\
\hline ES (ego strength) & $34.0 \pm 11.8$ & $32.9 \pm 12.0$ & 0.3 \\
\hline & & & \\
\hline
\end{tabular}

${ }^{*} \mathrm{p}<0.05,{ }^{* *} \mathrm{p}<0.001$. 


\section{Discussion}

The results of the present study suggest an association between DST nonsuppression and older age as well as higher scores on the MMPI depression and social introversion scales and lower scores on the hypomania scale.

The relationship between DST nonsuppression and older age, which was not present in the initial studies with the DST [review in 1], is currently supported by many recent studies $[10,13,15,27-33]$.

The sensitivity of the DST for major depression is rather low in this study (37\%), as compared to the usual sensitivity range (40-60\%) [1]. In fact, this lower sensitivity level may depend on the diagnostic group selected. Major depressive disorder is a rather wide nosologic group. In contrast, RDC for endogenous depression or DSM-III criteria for melancholia include only a subgroup of patients diagnosed as having a major depressive disorder. Therefore, the selection of a sample composed only of endogenous depressive or melancholic patients would have increased the sensitivity level of the DST.

The results of our study suggest a higher severity level of depressive psychopathology among DST nonsuppressor as compared to suppressor depressives. This association between DST nonsuppression and severity of depression had already been noted in three studies using Hamilton depression scale ratings [3-5], but negative results have also been published $[7,9,11,12,18]$. Several studies previously used MMPI scales in connection with the DST. Interestingly, our finding of significantly higher scores on the MMPI social introversion scale was already noted by Bryer et al. [13]. However, these authors did not find any other differences between nonsuppressor and suppressor depressives. Stokes et al. [20] were unable to find any association between DST nonsuppression and MMPI scale scores but they used a mixed diagnostic group which may have blurred characteristics among depressive patients. Norman et al. [21] did not find any differences between suppressors and nonsuppressors on any of the MMPI scales. However, a significantly higher proportion of suppressors exhibited personality dysfunction (shown by elevations on the psychopathic deviate MMPI scale associated with the paranoid or the hypomanic scale) than did the nonsuppressors. In line with this study, Szadoczki et al. [22] have reported that in a group of 'neurotic depressives', DST nonsuppressors had normal mean MMPI profiles while suppressors showed elevation on hypochondriasis, depression, hysteria and schizophrenia scales. Moreover, in a comparison of MMPI profiles of 33 depressed chil- dren and adolescents, Klee and Garfinkel [34] reported that the suppressor group presented peak elevations on the depression and psychopathic deviate scales while the nonsuppressor group peaked only on the depression scale. These last three studies suggest that DST suppressor depressives tend to have more severe personality difficulties, a finding that we do not confirm in our study.

The lack of difference on the MMPI anxiety scale between nonsuppressor and suppressor depressives is in agreement with the hypothesis of Carroll et al. [16] that DST results are related to depression and not to stress or anxiety. However, a recent study demonstrated the role of a stressful situation and of acute anxiety in the escape following dexamethasone among presurgical subjects [6], confirming older data showing an impaired suppression of 17-hydroxycorticosteroids in the urine of military trainees under emotional stress [35]. Moreover, Langer et al. [36] failed to observe abnormal DST results in depressed patients treated with high doses of diazepam, suggesting that hypersecretion of cortisol in some depressive patients is secondary to stress rather than to a specific hypothalamic-pituitary-adrenal dysfunction.

Sangal et al. [5] recently reported a significant correlation between post-DST cortisol level and 5 items from depression scales (suicidal self-depreciation, sadness, irritability, hopelessness and feeling of reduced competence) as well as 5 items from anxiety and somatic inventories (fears, tension, diarrhea, feeling overexcited and feeling uncomfortable). Reus [4] also noted that nonsuppressor psychiatric inpatients appeared to show more symptoms of anxiety, sleep disturbances, attentional difficulties and anergy. The higher frequency of sleep disturbances was confirmed by Nasr et al. [19], who also found more frequent paranoid symptoms. This last finding supports the higher rate of DST nonsuppression already noted in psychotic depression [11, 16-18].

In this context, our study suggests that among major depressive inpatients, DST nonsuppression relates to depressive/manic psychopathology rather than anxious psychopathology. Therefore, it favors the validity of the DST as a possible 'biological marker' of some subtypes of depressive disorders.

\section{References}

1 Carroll, B.J.: The dexamethasone suppression test for melancholia. Br. J. Psychiat. 140: 292-304 (1982).

2 Hirschfeld, R.M.A.; Koslow, S.H.; Kupfer, D.J.: The clinical utility of the dexamethasone suppression test in psychiatry. 
Summary of a National Institute of Mental Health workshop. J. Am. med. Ass. 250: 2172-2174 (1983).

3 Stokes, P.E.; Pick, G.R.; Stoll, P.M.; Nunn, W.D.: Pituitaryadrenal function in depressed patients: resistance to dexamethasone suppression. J. psychiat. Res. 12: 271-281 (1975).

4 Reus, V.I.: Pituitary-adrenal disinhibition as the independent variable in the assessment of behavioral symptoms. Biol. Psychiat. 17: 317-326 (1982).

5 Sangal, R.; Correa, E.T.; DePaulo, J.R.: Depression and anxiety inventories, and the dexamethasone suppression test. Biol. Psychiat. 19: 1207-1213 (1984).

6 Ceulemans, D.L.S.; Westenberg, H.G.M.; van Praag, H.M.: The effect of stress on the dexamethasone suppression test. Psychiat. Res. 14: 189-195 (1984).

7 Carroll, B.J.; Davies, B.M.: Clinical associations of 11-hydroxycorticosteroid suppression and non-suppression in severe depressive illness. Br. Med. J. $i$ : 789-791 (1970).

8 Brown, W.A.; Johnston, R.; Mayfield, D.: The 24 hour dexamethasone suppression test in a clinical setting: relationship to diagnosis, symptoms and response to treatment. Am. J. Psychiat. 136: 543-547 (1979).

9 Brown, W.A.; Shuey, I.: Response to dexamethasone and subtype of depression. Archs gen. Psychiat. 37: 747-751 (1980).

10 Asnis, G.M.; Sachar, E.J.; Halbreich, U.; Nathan, R.S.; Novacenko, H.; Ostrow, L.C.: Cortisol secretion in relation to age in major depression. Psychosom. Med. 43: 235-242 (1981).

11 Mendlewicz, J.; Charles, G.; Frankson, J.M.: The dexamethasone suppression test in affective disorder. Relationship to clinical and genetic subgroups. Br. J. Psychiat. 141: 464-470 (1982).

12 Giles, D.E.; Rush, A.J.: Relationship of dysfunctional attitudes and dexamethasone response in endogenous and nonendogenous depression. Biol. Psychiat. 17: 1303-1314 (1982).

13 Bryer, J.B.; Borrelli,, D.J.; Matthews E.J., Jr.; Kornetsky, C.: The psychological correlates of the DST in depressed patients. Psychopharm. Bull. 19: 633-637 (1983).

14 Saleem, P.T.: Dexamethasone suppression test in depressive illness: its relation to anxiety symptoms. Br. J. Psychiat. 144: 181184 (1984).

15 Brown, W.A.; Qualls, C.B.: Pituitary-adrenal disinhibition in depression: marker of a subtype with characteristic clinical features and response to treatment? Psychiat. Res. 4: 115-128 (1981).

16 Carroll, B.J.: Limbic system-pituitary-adrenal cortex regulation in depression and schizophrenia. Psychosom. Med. 38: 106-121 (1976).

17 Rudorfer, M.V.; Hwu, H.-G.; Clayton, P.J.: Dexamethasone suppression test in primary depression: significance of family history and psychosis. Biol. Psychiat. 17: 41-48 (1982).

18 Asnis, G.M.; Halbreich, U.; Nathan, R.S.; Ostrow, L.; Novacenko, H.; Endicott, J.; Sachar, E.J.: The dexamethasone suppression test in depressive illness: clinical correlates. Psychoneuroendocrinology 7: 295-301 (1982).

19 Nasr, S.J.; Pandey, G.; Altman, E.G.; Gibbons, R.; Gaviria, F.M.; Davis, J.M.: Symptom profile of patients with positive DST: a pilot study. Biol. Psychiat. 18: 571-574 (1983).

20 Stokes, P.; Stoll, P.; Mattson, M.; Sollod, R.: Diagnosis and psychopathology in psychiatric patients resistant to dexamethasone; in Sachar, Hormones, behavior, and psychopathology (Raven Press, New York 1976).

21 Norman, W.H.; Keitner, G.I.; Miller, I.W.: MMPI, personality dysfunction and the dexamethasone suppression test in major depression. J. affect. Dis. 9: 97-101 (1985).

22 Szadoczky, E.; Rihmer, Z.; Arato, M.; Fazekas, I.; Abonyi, E.: Adatok az un neurotikus depressziok heterogenitasahoz. A klinikai es neuroendokrinologiai elkulonites. Iehetosegei Ideggyogyaszati Szemie 36: 461-467 (1983).

23 Spitzer, R.L.; Endicott, J.; Robins, E.: Research diagnostic criteria. Rationale and reliability. Archs gen. Psychiat. 35: 773-782 (1978).

24 Carroll, B.J.; Feinberg, M.; Greden, J.; Tarika, J.; Albala, A.A.; Haskett, R.F.; James, N.M.; Kronfol, Z.; Lohr, N.; Steiner, M.; De Vigne, J.P.; Young, E.: A specific laboratory test for the diagnosis of melancholia. Archs gen. Psychiat. 38: 15-22 (1981).

25 Sulon, J.; Demey-Ponsart, E.; Bauduin, E.; Sodoyez, J.C.: Radioimmunoassay of corticosterone, cortisone and cortisol. Their application to human cord and maternal plasma. J. Steroid Biochem. 9: 671-676 (1978).

26 Lewi, P.J.; Pinchard, A.G.: An automated Minnesota Multiphasic Personality Inventory test. Acta psychol. 27: 397-399 (1967).

27 Tourigny-Rivard, M.F.; Raskind, M.; Rivard, D.: The dexamethasone suppression test in an elderly population. Biol. Psychiat. 16: 1177-1184 (1981).

28 Davis, K.L.; Davis, B.M.; Mathé, A.A.; Mohs, R.C.; Rothpearl, A.B.; Levy, M.I.; Gorman, L.K.; Berger, P.: Age and the dexamethasone suppression test in depression. Am. J. Psychiat. 141: 872-874 (1984).

29 Stokes, P.E.; Stoll, P.M.; Koslow, S.H.; Maas, J.W.; Davis, J.M.; Swann, A.C.; Robins, E.: Pretreatment DST and hypothalamicpituitary-adrenocrotical function in depressed patients and comparison groups. Archs gen. Psychiat. 41: 257-267 (1984).

30 Nelson, W.H.; Khan, A.; Orr, W.W., Jr.; Tamragouri, R.N.: The dexamethasone suppression test: interaction of diagnosis, sex, and age in psychiatric inpatients. Biol. Psychiat. 19: 1293-1304 (1984).

31 Jacobs, S.; Mason, J.; Kosten, T.; Brown, S.; Ostfeld, A.: Urinary-free cortisol excretion in relation to age in acutely stressed persons with depressive symptoms. Psychosom. Med. 46: $213-$ 221 (1984).

32 Fogel, B.S.; Satel, S.L.; Levy, S.: Occurrence of high concentrations of postdexamethasone cortisol in elderly psychiatric inpatients. Psychiat. Res. 15: 85-90 (1985).

33 De Vigne, J.P.; Depauw, Y.; Ansseau, M.; Castro, P.; D'Haenen, H.; Doumont, A.; Hubain, P.; Mendlewicz, J.; Pelc, I.; Toscano, A.; Charles, G.: Age and sex effects on the diagnostic power of the DST. Paper presented at the IVth World Congress of Biological Psychiatry (Abstract). Philadelphia, Sept. 1985.

34 Klee, S.H.; Garfinkel, B.D.: Identification of depression in children and adolescents. The role of the dexamethasone suppression test. J. Am. Acad. Child Psychiat. 23: 410-415 (1984).

35 Blumenfield, M.; Fose, L.; Richmond, L.; Beering, S.: Dexamethasone suppression in basic trainees under stress. Archs gen. Psychiat. 23: 299-304 (1970).

36 Langer, G.; Schönbeck, G.; Koining, G.; Lesch, O.; Schüssler, M.: Hyperactivity of hypothalamic-pituitary-adrenal axis in endogenous depresson. Lancet ii: 524 (1979).

Marc Ansseau, MD, PhD, Biological Psychiatry and Psychopharmacology Unit, Centre Hospitalier Universitaire (B 33), B-4000 Liège Sart Tilman (Belgium) 